\title{
GAMBARAN PENGETAHUAN ORANGTUA, DUKUNGAN KELUARGA, DAN STATUS IMUNISASI TERHADAP KEJADIAN DIFTERI PADA BALITA DI WILAYAH PUSKESMAS CILEUNGSI KABUPATEN BOGOR TAHUN 2018
}

\author{
Siti Halimatus Sa'diah ${ }^{1)}$, Fenti Dewi Pertiwi ${ }^{2)}$, Ichayuen Aviyanti ${ }^{3)}$
}

\author{
${ }^{1)}$ Konsentrasi Kesehatan Ibu dan Anak, Program Studi Kesehatan Masyarakat, Fakultas Ilmu Kesehatan, Universitas Ibn \\ Khaldun. \\ ${ }^{2)}$ Email: sitihalimatussadiah18@gmail.com \\ Program Studi Kesehatan Masyarakat, Fakultas Ilmu Kesehatan Universitas Ibn Khaldun Bogor. \\ Email: fenti.dewi.pertiwi@gmail.com \\ ${ }^{3)}$ Program Studi Kesehatan Masyarakat, Fakultas Ilmu Kesehatan Universitas Ibn Khaldun Bogor. \\ Email: ichayuen@gmail.com
}

\begin{abstract}
Abstrak
Difteri merupakan salah satu penyakit menular yang dapat dicegah dengan imunisasi. Menurut WHO pada tahun 2011 di Asia Tenggara Indonesia menduduki peringkat kedua dengan 806 kasus difteri. penelitian ini bertujuan untuk melihat gambaran pengetahuan orangtua, dukungan keluarga dan status imunisasi terhadap kejadian difteri. Metode penelitian ini menggunakan Rapid Assisment Procedure. Jumlah sampel sebanyak 10 orang dan data diperoleh dengan wawancara mendalam. Hasil yang diperoleh bahwa yang menyebabkan terjadinya difteri di wilayah Puskesmas Cileungsi karena kurangnya pengetahuan orangtua, dukungan keluarga terhadap jadwal pemberian imunisasi dan manfaat imunisasi serta ada satu kelompok yang menolak untuk imunisasi karena hal tersebut mangandung barang yang haram. Berdasarkan penelitian yang dilakukan diperoleh kesimpulan bahwa pengetahuan, dukungan keluarga dan status imunisasi memiliki pengaruh terhadap kejaidian difteri. Untuk itu, diharapkan Puskesmas setempat memberikan konseling dan pendekatan pada masyarakat yang masih menolak imunisasi, memberikan edukasi dengan cara penyuluhan serta memberikan penghargaan bagi orangtua yang memberikan imunisasi DPT lengkap sesuai jadwalnya.
\end{abstract}

\section{Kata kunci : Gambaran, Pengetahuan, Imunisasi DPT, Difteri}

\section{PENDAHULUAN}

Pada tahun 2011 di Asia Tenggara (South East Regional Office) Indonesia menduduki peringkat kedua dengan 806 kasus difteri setelah India dengan jumlah kasus difteri 3485, dan Nepal merupakan Negara ketiga dengan 94 kasus difteri. (WHO,2012) Penyakit infeksi akut yang disebabkan oleh bakteri Corynebacterium diphteria pada umumnya lebih banyak menyerang pada usia 5-7 tahun (Kemenkes, 2014).

Difteri masih menjadi masalah yang serius di Indonesia khususnya di Jawa Barat. Pada tahun 2016 penyebaran kasus difteri terjadi di 6 Kabupaten dan Kota Provinsi di Jawa Barat yaitu di Kabupaten Cirebon, Kabupaten Majalengka, Kabupaten Bogor, Kota Bekasi, Cimahi dan Kabupaten 
Indramayu. Kasus yang ditemukan di Jawa Barat ini terjadi pada anak usia 3-4 tahun. Meski demikian, orang dewasa juga tetap perlu waspada karena difteri bisa terjadi pada orang dewasa yang tidak memiliki kekebalan terhadap difteri (Kemenkes, 2018).

Tahun 2017 tiga Provinsi melakukan respon cepat terhadap kasus difteri, diantaranya Provinsi Banten, DKI Jakarta, dan Jawa Barat yang mulai melaksanakan ORI (Outbreak Response Immunization). Hal tersebut dilakukan karena terdapat 123 kasus di Jawa Barat dengan 13 kematian yang tersebar di 18 Kabupaten/Kota kasus terbanyak terjadi di purwakarta dengan 27 kasus di susul kerawang dengan 14 kasus, Provinsi Banten dilaporkan terdapat 63 kasus dengan 9 kematian dan DKI Jakarta terdapat 22 kasus (Kemenkes, 2017).

Pada tahun 2017, di Kabupaten Bogor terjadi KLB Difteri di Kp. Pondok Menteng Desa Citapen Kecamatan Ciawi dengan jumlah kasus, 1 kasus konfirmasi meninggal yaitu balita usia 5 tahun 8 bulan meninggal di RSUD Ciawi Bogor tanggal 16 Oktober 2016 dengan hasil pemeriksaan di RSUD Ciawi secara mikroskopis positif Corynebacterium diphteria dan 5 kasus suspek difteri. Pada saat penyelidikan epidemiologi ditemukan 5 kasus

\section{METODE}

Penelitian menggunakan pendekatan kualitatif dengan pengambilan data yang dilakukan di Puskesmas Cileungsi dengan sampel 8 orangtua balita, dan 2 petugas kesehatan. Variabel independen atau variabel bebas dari penelitian ini adalah pengetahuan, status imunisasi, dan dukungan keluarga. Variabel dependen atau variabel terikat dalam penelitian ini adalah gambaran pengetahuan orangtua mengenai imunisasi DPT terhadap suspek difteri dengan gejala demam, sakit tenggorokan, leher bengkak, sesak napas, dan adanya pseudomembran (Excecutive Summary kabupaten Bogor, 2016).

Kepala Bidang Pencegahan dan Pengendalian Penyakit (P2P) Dinas Kesehatan Kabupaten Bogor menyatakan jumlah kasus difteri sampai bulan November 2017 di Kabupaten Bogor terdapat 9 kasus. 1 diantaranya meninggal dunia dan merupakan warga Cileungsi (Radar Bogor, 2017). Penelitian ini dilakukan di wilayah Puskesmas Cileungsi, dari hasil laporan Dinas kesehatan Kabupaten Bogor tercatat kejadian Difteri selama 2 tahun terjadi berturut-turut memakan korban di wilayah Cileungsi dalam kurun waktu tahun 2011-2013, dan terjadi kembali pada tahun 2017 dengan jumlah 1 penderita yang meninggal dunia. Wilayah Cileungsi ini lebih sering terjadi difteri di bandingkan wilayah lain di Kabupaten Bogor (Profil Dinkes Kabupaten Bogor, 2015).

Penyakit difteri ini dapat dicegah dengan imunisasi DPT sesuai dengan Pengembangan Program Imunisasi (PPI) sebagai imunisasi dasar. Dan juga di lakukan pada usia 6-7 tahun (Sekolah Dasar kelas 1) pemberian Booster Difteri Toksoid (DT). (Ikatan Dokter Anak Indonesia, 2011).

kejadian difteri. Data yang digunakan dalam penelitian ini merupakan data primer dan sekunder. Data primer dalam penelitian ini merupakan data yang diperoleh secara langsung dari sumber data yang didapatkan dengan cara wawancara mendalam, dan data sekunder pada penelitian ini didapatkan dari hasil data yang sudah terkumpul di Dinas kesehatan Kabupaen Bogor dan Puskesmas Cilengsi. 


\section{HASIL DAN PEMBAHASAN}

Partisipan pada penelitian ini adalah orangtua yang memiliki balita baik yang aktif di imunisasi dan yang jarang di imunisasi. Latar belakang pendidikan SD,SMP, dan SMA. Semua partisipan adalah ibu rumah tangga.

Variabel yang di teliti pada penelitian ini adalah variabel pengetahuan, status imunisasi dan dukungan keluarga. Hasil penelitian menunjukan sebagai berikut:

1) Pengetahuan orangtua yang masih minim menganai imunisasi DPT terhadap kejadian difteri. Semua pemahaman partisipan adalah bahwa imunisasi hanya akan mencegah penyakit dan bahkan beberapa partisipan menyatakan tidak mengimunisasi anaknya karena masih memiliki pemahaman bahwa orangtua dulu tidak mengimunisasi anak balitanya. 3 dari 4 informan menyatakan tidak tahu manfaat dari imunisasi DPT. Pengetahuan yang kurang ini juga disebabkan oleh rendahnya pendidikan informan yang berlatar belakang SD dan SMP,

2) Status imunisasi yang juga masih minim. Hal tersebut disebabkan karena orangtua

\section{PENUTUP}

Ketiga variabel yang diteliti menyatakan bahwa pengetahuan, status imunisasi dan dukungan keluarga. Pengetahuan orangtua balita dalam aspek imunisasi DPT secara umum masih kurang. Terutama dalam hal manfaat imunisasi DPT, dengan begitu pengetahuan memiliki hubungan yang mempengaruhi terhadap imunisasi DPT.Status imunisasi balita yang tidak pernah di imunisasi sangat buruk yaitu ibu tidak pernah memberikan imunisasi kepada anaknya termasuk imunisasi DPT. Hal tersebut mempengaruhi terhadap kejadian penyakit difteri seperti telah diungkapkan tidak membawa balita ke posyandu atau pelayanan kesehatan untuk mendapatkan imunisasi DPT. Dengan alasan setelah imunisasi kesehatan anak menjadi tergangggu. 3 dari 4 informan yang jarang membawa anakanya ke pelayanan kesehatan untuk mendapatkan imunisasi DPT menyatakan tidak tahu dan tidak pernah mendengar imunisasi DPT. Hal tersebut yang kemudian menjadikan orangtua tidak datang ke Pelayanan kesehatan.

3) Dukungan kelurga, variabel ini juga menentukan sikap orangtua dalam mengambil keputusan untuk memberikan imunisasi DPT kepada balitanya. Baik informan yang selalu mengimunisasi DPT balitanya dan informan yang tidak mengimunisasi DPT baitanya sama-sama tidak memiliki dukungan dari keluarga. Hal tersebut dinyatakan oleh 3 informan yang selalu datang ke imunisasi DPT. "suka bareng bareng sih,banyakan// saya sendiir,paling bareng sama tetangga//, sendiri.",

oleh informan inti dan informan kunci. Oleh karena itu, status imunisasi DPT memliki hubungan untuk masa depan anak dalam mencegah penyakit difteri. Dukungan Keluarga memiliki hubungan yang tidak kalah penting dalam memberikan imunisasi DPT, tetapi beberapa informan di sini tidak mendapatkan dukungan keluarga bahkan ada yang melarang. Sehingga dukungan keluarga di sini sangat berhubungan dan mempengaruhi terhadap pengetahuan orangtua (ibu) dan juga terhadap pemberian imunisasi DPT yang merupakan pencegahan penyakit berbahaya difteri 


\section{DAFTAR PUSTAKA}

[1] Andareto, Obi. 2015. Penyakit Menular di Sekitar Anda. Jakarta: Pustaka ilmu Semesta

[2] Anurogo, Dito. 2016. The Art Of Medicine, Seni Mendeteksi, Mengobati, dan Menyembukan Penyakit dan Gangguan Kesehatan. Jakarta: PT Gramedia Pustaka Utam

[3] Arifin,dkk. 2016. Faktor Yang Behubungan Dengan Kasus Difteri Anak di Puskesmas Bangkalan Tahun 2016. Jurnal Berkala Epidemiologi Volume 5 Nomor 1.Januari 2016

[4] Arikunto, Suharsimi. 2013. Prosedur Penelitian Suatu Pendekatan Praktik. Jakarta: Rineka Cipta

[5] Dickegeorge. 1992. Imunisasi Dalam Praktek. Jakarta. Hipokrates

[6] Dinas Kesehatan. 2015. Profil Dinas Kesehatan Kabupaten Bogor 2015. Bogor: Dinkes Kabupaten Bogor

[7] Anonim, 2016. Profil Dinas Kesehatan Kabupaten Bogor 2016. Bogor. Dinkes Kabupaten Bogor

[8] Fajriyah, Ishmatul. 2014. Hubungan Pengetahuan Ibu dan Dukungan Keluarga Dengan Status Imunisasi Pada SUB PIN Difteri. Departemen Epidemiologi Fakultas Kesehatan Masyarakat Universitas

[9] Airlangga. Surabaya: Jurnal Berkala Epidemiologi Volume 2 Nomor 3 September 2014. 414-415
[10] Hidayat. Aziz. 2008. Pengantar Ilmu Keperawatan Anak. Jakarta: Salemba Medika

[11] Isbagio,dkk. 2004. Pengaruh Status Imunisasi Difteri Pertusis dan Tetanus Terhadap Respon Kekebalan Difteri dan Tetanus Pada Murid Kelas 1 Sekolah Dasar di Kecamatan Mandala. Buletin Penelitian Kesehatan Volume 32 Nomor 2 62-72

[12] Mulyadi dam Rinawati. 2013. Imunisasi Untuk Anak. Yogyakarta: Nurtha Medika

[13] Muryani,dkk. 2013. Tingkat Pengetahuan Ibu Tentang Difteri Berhubungan Dengan Perilaku Pencegahan Penyakit Difteri di Dusun Ngrame Kasihan Bantul. Jurnal JNKI,Volume 1 Nomor 2 61-65

[14] Mushilah,dkk. 2017. Hubungan Pengetahuan Ibu dan Dukungan Keluarga Terhadap Imunisasi dengan Status Imunisasi di Wilayah Kerja Puskesmas Se,por I. Stikes Muhammadiyah Gombong.

[15] Nanik,dkk. 2013. Hubungan Peran Ayah di Keluarga Dengan Keikutsertaan Balita Usia 2-24 Bulan Pelaksanaan Imunisasi DPT di Desa Pace Kecamatan Silo Kabupaten Jember. Artikel Ilmiah Hasil Penelitian Mahasiswa. 